\title{
LA PROTECCIÓN DE LOS CONSUMIDORES FINANCIEROS.
}

THE PROTECTION OF FINANCIAL CONSUMERS.

\author{
Recibido: febrero de 2013 - Revisado: agosto de 2013 - Aceptado: 30 de noviembre de 2013
}

Por: Mayda Soraya Marin Galeano. ${ }^{1}$

\section{RESUMEN.}

En este artículo se propone contrastar las diferentes legislaciones de protección a los consumidores financieros, observando el panorama colombiano con relación a otros países. El estudio se desarrolla en cuatro fases: en la primera, se expondrá un panorama general de los derechos de los consumidores financieros; en la segunda, se presentarán los indicadores construidos; la tercera, constará de la medición y comparación de la protección del consumidor financiero en los cinco países seleccionados (Chile, Colombia, Reino Unido, España y Estados Unidos); y finalmente, se propondrán hipótesis causales que expliquen la protección del consumidor financiero.

\section{PALABRAS CLAVE.}

Derechos del consumidor financiero, servicio público, control y fiscalización de los bancos, clausulas abusivas en contratos bancarios, defensor del Consumidor Bancario, habeas data, educación al cliente bancario.

\section{ABSTRACT.}

This article intends to contrast the different laws of protection to financial consumers, in which the Colombian view is being compared with the one from other countries. This study is developed in four stages: in the first one, a comprehensive overview of the financial consumer rights will be set out; in the second one, the built indicators will be shown; in the third one, the measurement and comparison of the financial consumer protection will be carried out in the five following selected countries: Chile, Colombia, United Kingdom, Spain, and The United States; and in the last one, causal hypotheses explaining the financial consumer protection will be proposed.

\section{KEY WORDS AND EXPRESSIONS.}

Rights of the financial consumer; Public service; Control and audit of banks; Abusive clause in banking contracts; Defender of the banking consumer; Habeas Data; Education to the banking client.

\footnotetext{
${ }^{1}$ Abogada y Socióloga de la Universidad de Antioquia, Magister y Candidata a Doctora en Derecho Procesal de la Universidad de Medellín.maydasoraya@gmail.com.
} 


\section{Introducción.}

La creación de legislaciones sobre la protección de los derechos de los consumidores financieros data desde 1980 (Mendoza, 2010, p 2). Desde dicha fecha, hasta la actualidad se plantean dudas acerca de los desarrollos que han tenido estas regulaciones, y sobre cuáles son los motivos o fundamentos por los que unos países dictan normas que estén más orientadas a proporcionar una verdadera protección al consumidor. Es en el entorno contemporáneo, donde surge este artículo que pretende realizar un análisis comparativo de las legislaciones de cinco países sobre la protección de los consumidores financieros. Planteándose como objetivos: identificar un conjunto de indicadores que permitan medir y comparar el nivel de protección del consumidor financiero y proponer hipótesis causales que expliquen los diferentes niveles de protección del consumidor financiero.

Panorama sobre los derechos de los consumidores financieros

La experiencia histórica muestra como los bancos tuvieron un gran crecimiento durante los siglos de XVIII, XIX y principios del siglo XX; estos realizaban actividades de depósito, servicios de crédito e intermediación financiera. Para esta última época el estado intervenía directamente la actividad de los bancos, regularizando la labor y protegiendo indirectamente al ciudadano, incluso existía el uso de las leyes comerciales para dirimir sus controversias. Sin embargo, la legislación vigente en los siglos pasados no contaba con una categoría de defensa al consumidor financiero.

Para finales del siglo XX el estado comienza a crear regulaciones para la protección de los usuarios bancarios con la finalidad de dar estabilidad económica y atenuar las crisis financieras pasadas y futuras (Pérez, 2009, p 57-58). Es en este momento, donde surge la protección legal de los derechos de los consumidores financieros y se origina la responsabilidad para los bancos de cumplir dicha normatividad. En 1980 surge uno de los hechos más relevantes que marcaría el surgimiento de la protección del consumidor como lo fue el consenso de Washington, en cabeza de Ronald Reagan y Margaret Thatcher, donde se fijan los principios neoliberales de reducción del estado, privatización y libertad de mercado. (García, 2010, p 24), los cuales pretenden una desregularización del sistema financiero. Paralelamente, otros estados comienzan a crear instrumentos normativos para la protección de los consumidores financieros, con el fin de proteger a los sectores más débiles en este entramado de relaciones y sobre todo animarles a participar e invertir en el sistema financiero.

No obstante, a pesar de las posiciones de los estados de intervenir o no al sector financiero, se evidencia que estas empresas son las más grandes del mundo y que sus intereses particulares han jugado en contra de los consumidores debido a su poder en el mercado. (Pérez, 2009, 50); esto se verifica en el ranking presentado por la revista Forbes, que según su listado anual, para el 2011, tiene como la empresa más grande del mundo a la entidad financiera JPMorgan Chase, la cual ocupa este lugar por segundo año consecutivo; hecho similar se ve en el segundo puesto, ocupado por el banco HSBC. En sintesis, entre las 20 empresas más importantes del mundo 10 de ellas pertenecen al sector financiero (Zajac, 2011). Caso similar se presenta en Colombia, donde el Grupo Bancolombia, para el 2011, encabeza la lista (Semana, 2011).

En Colombia hay dificultades con la aplicación de normas que regulan las relaciones adecuadas entre las entidades y los clientes, como se aprecia en el alto índice de reclamaciones por parte de los consumidores financieros: 1.286 en enero de 2005 mientras 
en septiembre de 2011 van más de 3367 quejas manteniendo el crecimiento exponencial pero conservando el porcentaje de casos que promedia en el $75 \%$ sobre casos de reclamación a entidades bancarias- (Superintendencia financiera de Colombia, 2000 a 2011). Además, hay una continua solicitud al congreso o a la presidencia por parte de los ciudadanos y organizaciones para realizar reformas para este sector.

La preferencia y el beneficio que trae el estudio de dicho tema se puede ver de la siguiente manera:

Es un tópico de importancia política dado que hay un gran interés por parte de los estados y de la comunidad internacional para formular politicas económicas que se encaminen a buscar la estabilidad del sistema financiero y de reforzar politicas educativas "In light of these issues, financial consumer protection should be reinforced and integrated with other financial inclusion and financial education policies. This contributes to strengthening financial stability" ${ }^{2}$ (OECD; G 20. 2011). Estas políticas económicas buscan resguardar la confianza pública en las entidades crediticias y a largo plazo promover la innovación, además se busca controlar a las entidades financieras y cobijar a los sectores de más bajos ingresos y bancarizar casi el total de la población.

Además, es trascendental y necesario para la sociedad que las regulaciones apunten a la enseñanza de los derechos financieros, incluyendo no solo a los marginados o analfabetas, sino también a la población instruida que desconoce los términos específicos, permitiéndoles tener criterios y estar informada. Convirtiéndola, en un instrumento pedagógico para formar a la sociedad en temas relacionados con la administración de los recursos económicos de manera sencilla y práctica, para que los consumidores se informen, sean prudentes, selectivos y sepan reclamar sus derechos.

Es por ello que en aras de comprender y explicar es necesario definir y enmarcar ciertas nociones que permitirán aclarar el propósito temático de este artículo:

-Protección del consumidor financiero: Son derechos de carácter jurídico que garantizan a un individuo o colectividad un equilibrio entre él como usuario de estos servicios y las entidades bancarias; estos derechos tienen el propósito de resguardar los intereses de los consumidores de servicios como depósitos, fiducias, créditos, transferencias, frente a las posibles irregularidades de las entidades financieras.

-Los consumidores son personas que realizan la actividad de comprar o utilizar ciertos servicios que son prestados por un tercero, llámese persona natural o empresa, que les proporciona un producto o servicio; específicamente, el consumidor financiero, requiere servicios vinculados con asuntos bancarios, bursátiles o negocios mercantiles.

Cuando se habla de la protección del consumidor financiero, se pretende hacer referencia a los derechos como la facultad que tiene la persona que usa los servicios bancarios para exigir todo aquello que la ley, los decretos, los actos administrativos, las resoluciones o incluso la jurisprudencia reiterativa, establece a favor de esas personas.

-Regulación financiera: Son una serie de normas o reglas creadas y ejecutadas por los gobiernos para garantizar la prestación de los servicios financieros (Pérez, 2009, p 57). Los estados ordenan o ponen en funcionamiento instrumentos de derecho para establecer la 
conducta adecuada entre los actores y los mercados financieros, además de establecer la supervisión por un órgano de control. Dentro de estas regulaciones financieras se encuentran las normas protectoras de los derechos de los consumidores. Todo esto, con la finalidad de compeler a las instituciones financieras a asumir comportamientos prudentes en la provisión del crédito (Beretta, 2009, 46).

...Los gobiernos regulan tanto a las instituciones como a los diferentes mercados que conforman el sistema financiero, fundamentalmente por cuatro razones: a. Para incrementar su transparencia, es decir, la información disponible para los inversores y los usuarios. b. Para mantener y mejorar la solvencia de los intermediarios financieros. c. Por razones de política monetaria. d. Por la existencia de riesgo sistémico (Pérez, 2009, p 57).”

-Sistema financiero: Está conformado por un conjunto de instituciones que incluye a los mercados, los intermediarios, las entidades financieras y las compañías cuya función es canalizar el dinero y colocarlo en forma de crédito o inversiones.

Este marco conceptual nos permite precisar que hay pocas investigaciones empíricas que indaguen por la protección que se ofrece a los consumidores financieros, y los estudios más adecuados por regla general son contratados por las entidades financieras u organismos como el Banco Mundial (Pinar, Ibrahim, Mylenko, 2011). Las investigaciones que se han hecho sobre este tema se centran en describir las legislaciones de los derechos del consumidor financiero en diferentes países (Arias, 2008), o grupos de estados (Engel, 1998; Pardos, 1998). Muchos estudios se concentran en relatar las experiencias de los estados en la aplicación de estos marcos normativos. ${ }^{3}$ Estos estudios analizan las legislaciones de los derechos del consumidor financiero de forma aislada, se centran en indicadores como el derecho de información, el control de los bancos, la seguridad electrónica, pero sin analizarlos de forma conjunta y sin construir un marco de indicadores para analizar la situación de forma comparativa.

Hay estudios comparativos sobre legislaciones de protección del consumidor financiero en Latinoamérica (Livacic y Sáez, 2001), en la Unión Europea (World Bank, 2008) y Estados Unidos (Nanto, Coordinator, 2009); en los que se justifican los derechos de los consumidores financieros dentro de los ordenamientos jurídicos actuales o la presentación del panorama de protección en diferentes estados. Muy pocas investigaciones cuentan con un enfoque empírico (Serna., Suárez., Restrepo, 2007) o con datos estadísticos (World Bank, 2008) ${ }^{4}$. En Colombia los trabajos sobre el tema no aportan evidencia empírica, esto se ve en trabajos como: el de Arias Barrera (2008) que se limita a realizar una descripción normativa y su aplicación, o el trabajo de Restrepo y Restrepo (2009) que efectúa una reseña sobre la crisis financiera de 2008, o bien Palomar Avilés (2004) quien en su tesis presenta el panorama del defensor del cliente comparándolo con otras legislaciones.

Los estudios sobre las causas de la protección del consumidor financiero son prácticamente inexistentes en Colombia, por lo que es necesario realizar un análisis de los factores que determinan la emergencia y el tipo de protección del consumidor para conocer qué políticas o medidas se deberian tomar para incentivar o cambiar la protección del consumidor.

Desde el campo de la sociología, los derechos de los consumidores financieros no han sido su preocupación central; Las temáticas que se han desarrollado son abordadas desde la cultura del consumo, los patrones de comportamiento de los consumidores (Ritzer, 2000), sobre 
cómo entender las necesidades del consumidor (García, 1995), la elección racional, los procesos socio-culturales del consumo (Baudrillard, 1979, 1974) y la dimensión económica del consumo.

Al mismo tiempo hay una necesidad de desarrollo empírico de la sociología del derecho en Colombia dado su carácter incipiente, donde se hace vital la aparición de estudios no centrados en la norma como tal, sino en las conductas o las relaciones sociales que explican la existencia de las normas; pretendiendo saber cómo influyen ciertos factores o fenómenos en la producción de una norma. Es por ello que el estudio desarrollado aporta a la cultura, a la economía, al derecho, a nuevas politicas, además permite a abrir el panorama de la protección de los consumidores financieros.

\section{Metodologia.}

El estudio se desarrolló en cuatro fases:

- Se realizó un análisis jurídico comparado entre las diferentes normas expedidas por los países frente a la protección de los derechos de los consumidores financieros.

- Se identifican indicadores construidos en la protección de los depositantes y la ejecución de la calidad de dicha protección dentro de dichas normativas;

- Se realiza la medición y comparación de la protección del consumidor financiero entre Reino Unido, Estados Unidos, España, Chile y Colombia; los dos primeros por ser los primeros en tener mercado financiero y los últimos tres por tener cambios considerables en pro de la protección de los consumidores financieros en los últimos 50 años y Colombia, como eje de análisis comparativo que sirve para contrastar las realidades sociales de los depositantes bancarios en la legislación del país.

- Para ellos se elaboraron hipótesis causales que expliquen la protección del consumidor financiero según los hallazgos de los puntos anteriores.

- Los datos se recopilaron de fuentes secundarias y revisión normativa y bibliográfica amplia.

\section{Resultados-discusiones.}

Los indicadores construidos.

El análisis comparativo se realizó observando las legislaciones existentes para la protección de los consumidores financieros en cinco países: en primer término Colombia, por estar inmerso en una serie de procesos liderados por la Superintendencia Financiera para dar garantias a los usuarios de estas entidades; en segundo lugar, Chile tomando en cuenta que es un referente latinoamericano en procesos bancarios; asimismo, por su reconocimiento internacional como una de las economías más sólidas; tercero, España, para entender los procesos de la Unión Europea en materia normativa bancaria, que además cuenta con un sistema normativo continental parecido al de Colombia y Chile; y por último, se encuentran el Reino Unido y Estados Unidos, por ser países de tradición del derecho de Common Law y por tener un mercado financiero reconocido a nivel mundial. 
La protección del consumidor en estos países se medirá a través de los siguientes indicadores que se explicaran en el siguiente cuadro, para dar a conocer cuándo se puede decir que hay mayor o menor amparo:

Imagen 1: Cuadro de indicadores (realización propia de la autora)

\begin{tabular}{|c|c|c|}
\hline Numero de indicador & Nombre del indicador & Explicación \\
\hline Indicador \# 1 & $\begin{array}{l}\text { Los bancos prestan un servicio } \\
\text { público }\end{array}$ & $\begin{array}{l}\text { Hay mayor prot ección de los consumidores sí se define como una } \\
\text { función propia del estado, permitiendo la intervención del estado para } \\
\text { dar garantías financieras a los ciudadanos. }\end{array}$ \\
\hline Indicador \# 2 & $\begin{array}{l}\text { Función de control y fiscalización } \\
\text { de los bancos }\end{array}$ & $\begin{array}{l}\text { Se presenta como mayor gara ntía cuando el estado puede controlar la } \\
\text { actividad bancaria a través de la creación de leyes especiales de control } \\
\text { y fiscalización y normas sancionadoras de malas prácticas bancarias. O } \\
\text { la posibilidad de autorregulación interna o externa. }\end{array}$ \\
\hline Indicador \# 3 & $\begin{array}{l}\text { Prohibición de clausulas abusivas } \\
\text { en contratos bancarios }\end{array}$ & $\begin{array}{l}\text { Como los estados crean herramientas practicas para que las entidades } \\
\text { financieras no realicen contratos perjudiciales para los consumidores. }\end{array}$ \\
\hline Indicador \# 4 & Prohibición de letra menuda & $\begin{array}{l}\text { Como los estado s crean estrategias para evitar el uso de la práctica de } \\
\text { la letra pequeña que no alcanzan a percibir los usuarios de estos } \\
\text { servicios. }\end{array}$ \\
\hline Indicador \# 5 & $\begin{array}{l}\text { Defensor del Consumidor } \\
\text { Bancario }\end{array}$ & $\begin{array}{l}\text { Observar cuáles son las facultades que le otorgan las leyes de los } \\
\text { estados para vigilar la actividad bancaria. }\end{array}$ \\
\hline Indicador \# 6 & $\begin{array}{l}\text { Secreto profesional o reserva } \\
\text { bancaria }\end{array}$ & $\begin{array}{l}\text { Es aquella entendida como la obligación contractual o legal que vincula } \\
\text { a los bancos como depositarios de cuentas a no revelar la información } \\
\text { sobre los montos o ca ntidades, ni los movimientos o circulantes de sus } \\
\text { clientes sin que medie orden judicial o acuerdo internacional. }\end{array}$ \\
\hline Indicador \# 7 & Habeas data & $\begin{array}{l}\text { Cómo se crean normas de protección que tienen las personas para } \\
\text { acceder a su información y poder corregir datos que } \\
\text { perjuicios. }\end{array}$ \\
\hline Indicador \# 8 & $\begin{array}{l}\text { Derecho a una Información } \\
\text { sencilla y clara }\end{array}$ & $\begin{array}{l}\text { Medir si existen normas que propendan por un lenguaje sencillo que } \\
\text { permita a las personas del común entender sus negocios con los bancos }\end{array}$ \\
\hline Indicador \# 9 & $\begin{array}{l}\text { Responsabilidad derivad a del } \\
\text { cumplimiento defectuoso o } \\
\text { incumplimiento de las } \\
\text { obligaciones }\end{array}$ & $\begin{array}{l}\text { Sí existen mecanismos de reclamación y coerción para que los bancos } \\
\text { cumplan con las obligaciones frente a sus clientes. }\end{array}$ \\
\hline Indicador \# 10 & Seguridad electrónica & $\begin{array}{l}\text { Si se vigila o si se implementa } \mathrm{n} \text { ayudas electrónicas para evitar la } \\
\text { defraudación a los consumidores. }\end{array}$ \\
\hline Indicador \# 11 & $\begin{array}{l}\text { Competencia desleal y acuerdos } \\
\text { sobre precios interbancarios }\end{array}$ & $\begin{array}{l}\text { Evitar las prácticas deshonestas que perjudiquen al consumidor y } \\
\text { sancionar los acuerdos que impongan a los usu arios pagos elevados en } \\
\text { sus costos bancarios. }\end{array}$ \\
\hline Indicador \# 12 & $\begin{array}{l}\text { Regulación de los créditos y } \\
\text { créditos hipotecarios }\end{array}$ & $\begin{array}{l}\text { Normas que eviten los cobros excesivos y las malas prácticas en el } \\
\text { otorgamiento de los créditos por parte de los bancos. }\end{array}$ \\
\hline Indicador \# 13 & $\begin{array}{l}\text { Regulación de las cuentas de } \\
\text { ahorro y contratos de depósito }\end{array}$ & Que se tengan límites para que los contratos de adhesión sean justos. \\
\hline Indicador \# 14 & $\begin{array}{l}\text { Autorización por parte del Estado } \\
\text { para abrir bancos }\end{array}$ & $\begin{array}{l}\text { Que el estado exija unas condiciones para la actividad bancaria y evite } \\
\text { el monopolio del mercado. }\end{array}$ \\
\hline Indicador \# 15 & $\begin{array}{l}\text { Fondo de garantías para las } \\
\text { instituciones financieras }\end{array}$ & $\begin{array}{l}\text { Tener una institución solida que responda cuando un banco se quiebre } \\
\text { o se declare insolvente. }\end{array}$ \\
\hline Indicador \# 16 & $\begin{array}{l}\text { Procedimientos para resolver } \\
\text { conflictos e ntre usuarios y } \\
\text { bancos }\end{array}$ & $\begin{array}{l}\text { Que se cuente con mecanismos judiciales y alternativos, eficaces para } \\
\text { dirimir los conflictos entre consumidores y bancos. }\end{array}$ \\
\hline Indicador \# 17 & Educación al cliente bancario & $\begin{array}{l}\text { Que exista un sistema integrado para que el consumidor comprenda } \\
\text { cómo funciona el sistema, que evite mal uso del mismo y que tenga el } \\
\text { conocimiento para hacer sus reclamaciones. }\end{array}$ \\
\hline Indicador \# 18 & $\begin{array}{l}\text { Revisión por parte de una } \\
\text { institución de control de los } \\
\text { reglamentos generales de ciertos } \\
\text { contratos. }\end{array}$ & $\begin{array}{l}\text { Que exista un órgano encarga do de revisar los contratos bancarios } \\
\text { cuando existan inconformidades o dudas por parte del consumidor } \\
\text { financiero }\end{array}$ \\
\hline
\end{tabular}


Análisis de resultados: Medición y comparación de la protección del consumidor financiero.

Los bancos prestan un servicio público

En Chile no se le atribuye, ni desde la constitución o normatividad la función pública a los bancos; sin embargo desde la teoría funcionalista dichas entidades cumplen con un servicio público. Mientras en España se tienen los artículo 40, 51 y 128 de la Constitución y la Ley 13/1994 que en su artículo 1 dice que "El Banco de España es una entidad de Derecho público"; en Colombia se dice explícitamente que es un servicio público, y que el Banco de la República se rige como persona jurídica de derecho público según los artículos 78, 150, 335 y 371 de la Constitución.

Por su parte Estados Unidos no tiene ninguna norma en la constitución que regule a los bancos como servicio público y mucho menos tiene un único banco que cumpla con dichas funciones, ya que el mismo se divide por distritos ${ }^{5}$ y se dirige por sus gobernadores. ${ }^{6}$ Lo mismo encontramos al Reino Unido, que no cuenta con una constitución oficial, pero la misma cuenta con un banco central que actualmente es de carácter público y según el Bank of England Act (1946 y 2009) ${ }^{7}$ le concede la capacidad de estabilizar, lo considera de interés público y lo encumbra como protector de los depositantes del estado.

Función de control y fiscalización de los bancos.

Chile desde su Constitución le da la función de control y regulación al banco central, lo cual se observa en sus artículos 108 y 109, la Ley $N^{\circ}$ 18.840, Ley General de Bancos D.F.L. 3 de 1997, Ley N²0.400 y D.O. 27.11.2009. Mientras que en España en desarrollo del artículo 40 constitucional se crea la Ley 13/ 1994 artículo 1 y la Ley 26/1988, (BOE de 30) que determina las sanciones y los tipos de sanción y regulación a los bancos. En Colombia se encuentra regulado en el artículo 371 de la constitución de 1991, que a través del Banco de la República cumplirá la función fiscal, la coordinación y la política económica general, además la Ley 31 de 1992 le da amplias facultades sancionatorias y de regulación bancaria.

En los Estados Unidos por medio del The Federal Reserve Act se le confieren poderes de regulación y control a todo el sistema bancario, el cual se puede ver referenciado en la Section 11. Powers of Board of Governors of the Federal Reserve System en estos artículos se aprecian la cantidad de funciones y posibilidades de regular el mercado, no obstante la mesa de gobernadores generalmente no logra ponerse de acuerdo a tiempo para lograr resolver los problemas de control financiero. Finalmente encontramos al Reino Unido que por medio de su banco de Inglaterra, regulado por el "Bank of England Act 1946, the charter of the corporation of the governor and company of the Bank of England de 1998, Bank of England Act 1998, y el Banking Act $2009^{\prime 8}$, le da facultades para intervenir y cumplir con el fin de regulación y control de los bancos en pro de la protección de los consumidores o depositantes.

Prohibición de cláusulas abusivas en contratos bancarios.

En el caso de Chile se tiene esta prohibición en la Ley 19.955 y Ley 19.496, modificadas por la Ley 20555 de 2011. En el caso de España, se prescribe en la Ley 7 de Condiciones Generales de la Contratación de 1998, la Directiva Europea 93/ 13 y el Real Decreto Legislativo 1/2007 que lo regula en su titulo 2. En Colombia se encuentra estipulado en la ley 1328 de 2009 sobre el régimen de protección del consumidor financiero, regulado en su artículo 11 a 12 del título V, además del estatuto del consumidor ley 1480 de 2011. 
Ahora bien en los Estados Unidos no se dio una ley especifica que concediera derechos al consumidor, sin embargo se creó por medio del Dodd-Frank Wall Street Reform and Consumer Protection Act una entidad de protección del consumidor, que fue regulada por medio del Title X-Bureau Of Consumer Financial Protection y que dentro de su articulado más específicamente en su Sec. 1031 crea la prohibición al decir "Prohibiting unfair, deceptive, or abusive acts or practices". El Reino Unido por medio de § 1692d. Harassment or abusesi, la Unfair Contracts Terms Act de 1977establece una protección aplicable, tanto a consumidores como a profesionales y la Unfair Terms in Consumer Contract Regulations (1999), la cual toma la directiva CE 13/93.

Prohibición de letra menuda.

Chile la prescribe en la Ley 19.955 y Ley 19.496 , en su artículo $17^{9}$, sin embargo, parece tener inconsistencias fundamentadas en una prerrogativa dirigida a los contratos redactados en otros idiomas, lo que resta credibilidad a la universalidad de la ley, no obstante, la Ley 20555 de 2011 intenta aclararlo en su artículo 17B "promover su simplicidad y transparencia". España, lo regula la Ley 7 de Condiciones Generales de la Contratación de 1998, la Directiva Europea 93/13 y el Real Decreto Legislativo 1/2007 en su artículo $80^{10}$. En Colombia es regulado por la ley 1328 de 2009 sobre el régimen de protección del consumidor financiero, en su artículo 7 numeral f, además del estatuto del consumidor, ley 1480 de 2011 que en su artículo 37 dice "en los contratos escritos, los caracteres deberán ser legibles a simple vista y no incluir espacios en blanco".

En lo referente a los Estados Unidos este tipo de competencias se atribuyen al Dodd-Frank Wall Street Reform and Consumer Protection Act por medio del Title X-Bureau Of Consumer Financial Protection en su Sec. 1032. Disclosures (2) Format, que crea la prohibición al decir “ (1) shall contain a clear and conspicuous disclosure that, at a minimum (A) uses plain language comprehensible to consumers; (B) contains a clear format and design, such as an easily readable type font; and (C) succinctly explains the information that must be communicated to the consumer."; por último el Reino Unido lo regula por medio de la Unfair Contracts Terms Act de 1977 y la Unfair Terms in Consumer Contract Regulations (1999), "Written contracts" en su artículo 7.-(1) "A seller or supplier shall ensure that any written term of a contract is expressed in plain, intelligible language. (2) If there is doubt about the meaning of a written term, the interpretation which is most favourable to the consumer shall prevail but this rule shall not apply in proceedings brought under regulation 12", además de la directiva CE 13/93 y el acuerdo de Brussels de 1993.

Defensor del Consumidor Bancario.

Chile lo normaliza en la Ley 20555 de 2011 que crea un ente encargado de la protección del consumidor denominado Servicio Nacional del Consumidor (SERNAC), el cual fue modificado por la ley del consumidor 19.496, que creo "El mediador y el árbitro financiero". Este defensor hace parte de la Asociación de Bancos e Instituciones Financieras de Chile (ABIF). Situación parecida a lo que ocurre en Colombia, que por medio de la ley 795 de 2003 en su artículo 24 le da facultades al defensor, pero a la vez lo amarra, como parte del funcionamiento de los bancos.

Por su parte España desde el año de 1988 cuenta con la Ley 26/1988, de 29 de julio (BOE de 30) acerca de la disciplina e intervención de las entidades de crédito que facultan al Banco de 
España en su artículo 48 en su numeral 2 a su "Ministro de Economía y Hacienda para (...) presidir las relaciones entre las entidades de crédito y su clientela" e imponer sanciones ante el incumplimiento.

En Estados Unidos la Ley Securities Exchange Act Of 1934 creó una comisión llamada Securities and Exchange Commission de la cual dependia el Office of the Investor Advocate, que en la práctica era el defensor del cliente; sin embargo esta figura fue considerada insuficiente y por lo tanto con la Dodd-Frank Wall Street Reform and Consumer Protection Act, se estableció en su Sec. 919D el Ombudsman. Para terminar, el Reino Unido por medio del Parliamentary Commissioner Act 1967 crea la figura del Parliamentary Commissioner, este parlamentario se comisionaba para todo tipo de investigaciones de carácter administrativo, dentro de las cuales se encontraban las quejas de los usuarios financieros, esta figura luego va a ser reemplazada por la Scotland Act 1997 en la que se le asignan sus competencias y es complementada por la del The Financial Services and Markets Act 2000 en la cual se le atribuyen más funciones y esquemas de trabajo y que será complementado por el Public Services Ombudsman (Wales) Act 2005 y que actualmente es canalizada por la Financial Ombudsman Services.

Secreto profesional o reserva bancaria.

Chile tiene los bancos sujetos al secreto bancario según la Ley general de bancos artículo 14 (D.L. 1.097 ART.13 bis), 18bis (Art. $3 \mathrm{~N}^{\circ} 2$ Ley N² 20.190 Art. Nuevo Agregado), 82, 154 (D.F.L. 252 ART. 20). En Colombia la protección de la reserva bancaria es regulada constitucionalmente en su artículo 74 al decir "El secreto profesional es inviolable."

En el caso de España, esta se regula por medio de Real Decreto Legislativo 1298/1986, capítulo IV artículo 6, en la Resolución de 28 de marzo de 2000, del Consejo de Gobierno del Banco de España, Sección 7. a artículo 17 en el cual se habla del deber de secreto; en la Ley 24/1988, de 28 de julio, referente al Mercado de Valores (BOE de 29) Artículo 83, 85 y principalmente el 90 aunada a la Directiva 2000/12/CE del Parlamento Europeo en su artículo 30, finalmente se encuentra la Ley 13/1994, (BOE de 2) que en su artículo 6 regula "El deber de secreto".

En lo referente a los Estados Unidos la reserva bancaria se regulan en la Sec. 1102 "Government authority may have access to or obtain copies of, or the information contained in the financial records of any customer from a financial institution unless the financial records are reasonably described"11 , esta norma actualmente hace parte del código civil de los Estados Unidos (Codified to 15 U.S.C. 1601 note). Sin embargo, esta se puede ver limitada por órdenes judiciales y gubernamentales como lo previsto por la Anti-Drug Abuse Control Act, el Bank Secrecy Act, la Annunzio-Wylie Money Laundering Act, el USA Patriot Act, la Prevention Reauthorization Act, el Intelligence Reform and Terrorism Prevention Act y el USA Patriot Act Additional Reauthorizing Amendments Act que han afectado directamente este tipo de legislaciones (Bartels y Arias, 2011). El Reino Unido que por medio de la Data Protection Act 1998, protege el secreto profesional, además de sancionar cualquier práctica realizada por los funcionarios encaminada a la divulgación de información privilegiada de los clientes. 
Habeas data.

Chile tiene la Ley 19.628 en la cual se protegen los datos de carácter personal en su artículo 12. En el caso de España, esta se regula desde la constitución de 1978 desde su artículo 18.4 se dispone: "La Ley limitará el uso de la informática para garantizar el honor y la intimidad personal y familiar de los ciudadanos y el pleno ejercicio de sus derechos". En Colombia el habeas data es regulada constitucionalmente en su artículo 15, la Ley 1266 de 2008 y concordada con la ley estatutaria 1581 de 2012.

En lo referente a los Estados Unidos el habeas data es protegido por el The Privacy Act of 1974 que reforma el código civil en sus artículos 5 U.S.C. $\S 552^{\mathrm{a}}$ en la cual se dan las normas y principios para actuar y reafirmar este derecho. El Reino Unido lo protege por medio de la Data Protection Act 1998.

Derecho a una Información sencilla y clara.

Chile la observa en la Ley 19.955 artículo 17 estableciendo el tamaño de la letra y optándose por el uso del español. En el caso de España, esta se regula por medio de la Ley 7 de Condiciones Generales de la Contratación de 1998, se refiere a entenderse como no incorporado aquellos que se entiendan como "Las que sean ilegibles, ambiguas, oscuras e incomprensibles" la Directiva Europea 93/13 la cual en su artículo 5 se refiere a que las "cláusulas se redacten de manera clara y comprensible" y el Real Decreto Legislativo 1/2007 que lo regula en su artículo 60, 69, 111 y 152 al decir "de forma clara y comprensible". En Colombia es regulado por la ley 1328 de 2009 sobre el régimen de protección del consumidor financiero, en su artículo 7 numeral f que dice que se debe optar por información clara a simple vista y sin espacios en blanco.

En lo referente a los Estados Unidos este tipo de competencias se atribuyen al Dodd-Frank Wall Street Reform and Consumer Protection Act que creó la entidad de protección del consumidor y que fue regulada por medio del Title X-Bureau Of Consumer Financial Protection y que dentro de su articulado más específicamente en su Sec. 1032. Privilegiando el lenguaje claro y comprensible; por último, el Reino Unido que por medio de la Unfair Contracts Terms Act de 1977 modificado por la Unfair Terms in Consumer Contract Regulations (1999), el cual se refiere en a "Written contracts" en su artículo 7.—(1) "A seller or supplier shall ensure that any written term of a contract is expressed in plain, intelligible language. (2) If there is doubt about the meaning of a written term, the interpretation which is most favourable to the consumer shall prevail but this rule shall not apply in proceedings brought under regulation 12".

Responsabilidad derivada del cumplimiento defectuoso o incumplimiento de las obligaciones.

Chile se regula en la Ley 19.955 que reforma la Ley 19.496, y al artículo 3 numeral b) al decir "El derecho a la reparación e indemnización adecuada y oportuna de todos los daños materiales y morales en caso de incumplimiento de cualquiera de las obligaciones contraídas" y la Ley 20555 de 2011. En el caso de España, está en el Real Decreto Legislativo $1 / 2007$, artículo 112 cuando se refiere a las consecuencias del incumplimiento "El contrato celebrado o la oferta realizada con infracción de los requisitos establecidos por los artículos 69.1 y 111 podrán ser anulados a instancia del consumidor y usuario." Las consecuencias del incumplimiento en Colombia es regulado por la ley 1328 de 2009 en su artículo 21. 
En lo referente a los Estados Unidos se encuentra en Securities Exchange Act Of 1934 en su sección 29 respecto de la valides de los contratos considera que la consecuencia del incumplimiento es la nulidad y la 42 USC § 9607 - Liability que permite reclamar la responsabilidad derivada de los contratos. Por último encontramos al Reino Unido que por medio de la Unfair Contracts Terms Act de 1977 se refiere en su artículo 16 que se refiere a la responsabilidad ante el incumplimiento a "Liability for breach of duty".

Seguridad electrónica.

Chile encuentra difuminada su legislación específicamente en la Ley 20009 de 2005 sobre tarjetas de crédito, la ley general de bancos 20.448 de 2010, la ley 19628 de 1999 respecto de los datos personales electrónicos, reformada por la ley 19.799 de 2002 y la Ley 19.955 que modifica la Ley 19.496, en su artículo 12a referentes al contrato electrónico y en el artículo 17D de la Ley 20555 de 2011. En España se recoge en la Ley 21/2011, de 26 de julio, de dinero electrónico. (BOE de 27) "El objeto de esta Ley es la regulación de la emisión de dinero electrónico, incluyendo el régimen jurídico de las entidades de dinero electrónico y la supervisión prudencial de estas entidades". En Colombia es regulado por la ley 1328 de 2009 en su artículo 7 numeral q) que dice "Disponer de los medios electrónicos y controles idóneos para brindar eficiente seguridad a las transacciones, a la información confidencial de los consumidores financieros y a las redes que la contengan" también en el numeral r), artículo 9 paragrafo1.

En lo referente a los Estados Unidos se encuentra en The Electronic Fund Transfer Act (EFTA) (15 USC 1693 et seq.) of 1978 y modificado por él Dodd-Frank Wall Street Reform and Consumer Protection Act en la Sec. 1084. Amendments to the Electronic Fund Transfer Act y como se observa " $\$ 902$. Findings and purpose, b) It is the purpose of this title to provide a basic framework establishing the rights, liabilities, and responsibilities of participants in electronic fund transfer systems. The primary objective of this title, however, is the provision of individual consumer rights" ${ }^{\prime 2}$. Por último encontramos al Reino Unido donde la Financial Services and Markets Act 2000 regula el mercado y el sistema financiero y sus diferentes modalidades en las que se encuentra la The Electronic Money Regulations 2011 "enabling applications to become an authorised electronic money institution and for the variation of an authorisation" y la regulación propia de la Comunidad Europea.

Competencia desleal y acuerdos sobre precios interbancarios.

Chile desde el Decreto Ley $\mathrm{N}^{\circ} 211$, de 1973 dio los primeros pasos en pro de la regulación de la competencia desleal, creando además el Tribunal de la Defensa de la Libre Competencia, actualmente esta se ve regulada por la Ley 20169 de 2007, marco general, sin embargo no se especifica para las entidades bancarias. España se regula en la Ley 29 de 2009, "por la que se modifica el régimen legal de la competencia desleal y de la publicidad para la mejora de la protección de los consumidores y usuarios". En Colombia se cuenta con el Decreto 663 de 1993 que en su capítulo XIV, artículo 98 prohíbe "todos los acuerdos o convenios entre empresarios".

Estados Unidos lo regulo inicialmente en el The Sherman Antitrust Act de 1890 y luego va modificar por medio del Federal Trade Commission Act, § 5, 15 U.S.C. § 45 que modifica el código civil en su title 15-commerce and trade. Para terminar este apartado, el Reino Unido trabaja en el tema por medio de la ley Competition Act 1998 el cual se refiere "An Act to make provision about competition and the abuse of a dominant position in the market; to confer 
powers in relation to investigations conducted in connection with Article 85 or 86 of the treaty establishing the European Community; to amend the Fair Trading Act 1973"

Regulación de los créditos y créditos hipotecarios.

La legislación Chilena tiene varias regulaciones que van desde el artículo 17D de la Ley 20555 de 2011, la Ley 18840 de 1090 en su Artículo $3^{\circ}$ y la Ley N² 20.448 de 2010 que establece a la Superintendencia de Bancos e Instituciones Financieras. Para Colombia lo regula la Ley 31 de 1992, el Decreto 663 de 1993 o Estatuto Orgánico del Sistema Financiero y se tramita un Proyecto de Ley el cual establecería un nuevo sistema de créditos hipotecarios. Para el caso de España se regula por medio de la Orden EHA/2899/2011, de 28 de octubre, de transparencia y protección del cliente de servicios bancarios, que en su artículo 1 garantiza el adecuado nivel de protección de los clientes de entidades de crédito, complementada por medio de la Circular 5/2012, de 27 de junio, del Banco de España. ${ }^{13}$

En los Estados Unidos, la regulación se encuentra sumergida en el "Dodd-Frank

Wall Street Reform and Consumer Protection Act" sin embargo este tipo de regulación no le otorga la facultad al estado para determinar los máximos o mínimos, y queda en manos de la reserve federal la autorregulación bancaria y la Mortgage Reform And Anti-Predatory Lending Act para evitar los prestamos abusivos. El Reino Unido realiza la labor legislativa por medio del Consumer Credit Act 1974 este regula no solo el crédito común, sino el régimen de hipotecas y en lo no regulado en este instrumento se normaliza por el Bank of England Act 1998.

Regulación de las cuentas de ahorro y contratos de depósito.

Chile a través de la Ley 18840 de 1989 le confirió facultades al banco central para regular las cuentas de ahorro y los contratos de depósito especialmente en su artículo 35 numeral 1. Para Colombia este aparte se ve regulado por el artículo 16 de la Ley 31 de 1992 referente a las funciones de la Junta Directiva del Banco de la República, en las que se le atribuye la autoridad para "adoptar las medidas monetarias, crediticias y cambiarias", además de los artículos 1400 y 1382 del Código de Comercio y el artículo 127 y siguientes del Estatuto Orgánico del Sistema Financiero. En España se regula por medio del artículo $1^{\circ}$ del Real Decreto Legislativo 1298/ 1986 de conformidad con la Ley 26/ 1988, y la Ley 13/ 1994.

Los depósitos y su regulación en los Estados Unidos se encuentran en el código civil federal en la PART 204-Reserve Requirements of Depository Institutions (Regulation D) este se enumera desde la § 204.1 a § 204.136, además del Monetary Control Act of 1980. El Reino Unido realiza la labor legislativa por medio del Banking Act 1987 y el Bank of England Act 1998.

Autorización por parte del Estado para abrir bancos.

La creación de los bancos en Chile se ve regulada por parte del estado con la Ley General de Bancos modificada por la Ley $\mathrm{N}^{\circ} 20.448$ de 2010 que en su título II, deja en manos de la Superintendencia de Bancos e Instituciones Financieras su autorización, implementación y cumplimiento. Mientras en España, la formación de bancos se ve regulada por el Real Decreto 1245/1995 que en su Título I sobre el régimen jurídico de la creación de bancos y especialmente en el artículo 1 numeral 1, señala que "Corresponderá al Ministro de Economía y Hacienda, previo informe del Banco de España, autorizar la creación de bancos". 
En Colombia se encuentra regulado por el decreto 663 DE 1993 o Estatuto Orgánico del Sistema Financiero en su parte III, capítulo I. articulo 53 numeral 1 delegándose dicha función a la Superintendencia.

Estados Unidos no hay un banco central que lo autoriza, esto corresponde a cada distrito; Finalmente encontramos que en el Reino Unido es el banco de Inglaterra y el ministerio de hacienda quienes lo regulan, además de las normas tales como Bank of England Act 1946, the charter of the corporation of the governor and company of the Bank of England de 1998, Bank of England Act 1998, y el Banking Act 2009.

Fondo de garantias para las instituciones financieras.

Chile tiene un fondo de garantías regulado en la Ley General de Bancos modificado por la Ley $\mathrm{N}^{\circ} 20.448$ de 2010 que en su artículo 144 prescribe que“...Dicha garantía favorecerá solamente a las personas naturales y cubrirá el 90\% del monto de la obligación". Para los españoles la protección frente a las quiebras bancarias se da por medio del Real Decreto $2606 / 1996$ que estipula que no solo es para los ahorradores, sino para las cooperativas de crédito por medio del Real Decreto-ley 16/2011. Colombia crea el fondo de garantías por medio del decreto 663 DE 1993 o Estatuto Orgánico del Sistema Financiero en su artículo 51 y la Ley 117 de 1985 crea el FOGAFIN que asegura los depósitos en 20.000.000 millones de pesos por depositante.

Los Estados Unidos por medio de la norma incluida en el código federal 12 U.S.C. § 1811: US Code - Section 1811, establece un Federal Deposit Insurance Corporation para asegurar los depósitos bancarios de asociaciones de ahorro; por su parte el Reino Unido lo regula por medio del Banking Act 2009' que en su Part 2 hace referente a la insolvencia y a su vez remite al Part 4 of the Financial Services and Markets Act 2000, y que igualmente redirecciona a The Financial Services and Markets Act 2000 (Transitional Provisions, Repeals and Savings) (Financial Services Compensation Scheme) Order 2001, en la cual se protegen los depósitos y se crea un esquema de amparo denominado "Board means the Policyholders Protection Board or the Deposit Protection Board" creada por medio del The Deposit Protection Board (Increase of Borrowing Limit) (No. 2) Order 1990.

Procedimientos para resolver conflictos entre usuarios y bancos.

Para el caso de Chile se encuentran regulados en la Ley 20555 de 2011, el Servicio Nacional del Consumidor (SERNAC), la ley 19.496 y complementado por la Asociación de Bancos e Instituciones Financieras de Chile (ABIF) pero todos buscan la conciliación. España desde el Ministerio de Economía y Hacienda por su parte lo regula por medio de la Ley 26/1988, (BOE de 30) además de las circulares dentro de las que se encuentra la Circular n. ${ }^{\circ} 8 / 1990$, (BOE de 20) a lo que se le suma el Real Decreto 303/2004, y la Orden ECO/734/2004 que pretende la resolución del conflicto. En Colombia se normaliza por la ley 795 de 2003 del Estatuto Orgánico del Sistema Financiero y la ley 1328 de 2009 sobre el régimen de protección del consumidor financiero, que en su artículo 8 crea las políticas, procedimientos y trámites, esta apunta a la solución de conflictos de forma consensuada, a lo anterior se suma lo regulado por el código general del proceso ley 1564 de 2012 en su artículo 24 Numeral 2, referente a las funciones jurisdiccionales de la superintendencia financiera. Para los Estados Unidos se tiene la Dodd-Frank Wall Street Reform and Consumer Protection Act y the Securities Exchange Act of 1934, en ellas se crean procedimientos de tipo proceso judicial con un juicio final. Finalmente el Reino Unido por medio de The Financial Services and Markets Act 2000 y 
el Public Services Ombudsman (Wales) Act 2005 que igualmente garantizan un proceso jurídico.

Educación al cliente bancario.

En Chile se encuentra contenida en la Ley $\mathrm{N}^{\circ} 19.496$ como un derecho, dejando en manos del Servicio Nacional del Consumidor la labor de su implementación, pero la misma no se dirige a la educación de carácter público. En España la educación se ve regulada por elReal Decreto Legislativo 1/2007, referente al consumidor financiero. Esta se ve implementada por medio de la Comisión Nacional del Mercado de Valores (CNMV) y el Banco de España (BE) quienes han elaborado un Plan de Educación Financiera para los usuarios, actuales y futuros, de servicios financieros. En Colombia la educación está contenida en la ley 1480 de 2011 y en la ley 1328 de 2009, sin embargo deja la labor educativa en las mismas entidades financieras. Pero esta no tiene la pretensión de hacer parte del sistema educativo del país.

En Estados Unidos por medio del "Dodd-Frank Wall Street Reform and Consumer Protection Act' y por el US Code, Financial Information Unit además de que entrega en manos del "Ombudsman" la implementación de la educación en entidades educativas estatales y privadas como requisito en la educación básica lo cual se ejecuta desde 1965. El Reino Unido lo regula por medio del Financial Services Act 2010 que crea un organismo público denominado "Financial Services Authority" FSA y va dirigido a la educación pública y privada.

La revisión por parte de una institución de control de los reglamentos generales de ciertos contratos.

Chile por medio del decreto ley 3 de 1997 Ley General de Bancos crea la Superintendencia de Bancos e Instituciones Financieras que regula vigila e indica los parámetros para los contratos de tarjetas de crédito, cuentas corrientes e hipotecas. En España se concentra en la comisión nacional del mercado de valores creada por la ley 24 de 1988, y con funciones amplias sobre el mercado de valores. Colombia cuenta con la superintendencia bancaria desde 1923, pero solo después del Decreto 4327 de 2005 se fusiona en una sola entidad llamada Superintendencia Financiera de Colombia que une los valores y la banca, además se encarga de regular los créditos, valores, pensiones, fiducias y portafolios de inversión.

En los Estados Unidos, las entidades reguladoras son muchas másdefinidas y dispersas, las cuales son Securities and Exchange Commission (SEC), Financial Industry Regulatory Authority (FINRA), Commodity Futures Trading Commission (CFTC), Federal Reserve System ("Fed"), Federal Deposit Insurance Corporation (FDIC), Office of the Comptroller of the Currency (OCC), National Credit Union Administration (NCUA), Office of Thrift Supervision (OTS). En el Reino Unido la función de supervisión del sistema se encuentra a cargo del Banco de Inglaterra, HM tesoro y la autoridad del servicio financiero, el "Responsibility for financial stability in the UK is shared by HM Treasury, the Bank of England, and the Financial Services Authority (FSA)"14

La presente grafica muestra una puntuación sobre la existencia y la calidad de las legislaciones sobre la protección a los consumidores financieros y es un punto de partida que sirve para visualizar, comparar, promover investigaciones y crear hipótesis 
Imagen 2: Cuadro de resultados comparativos entre países (realización propia de la autora)

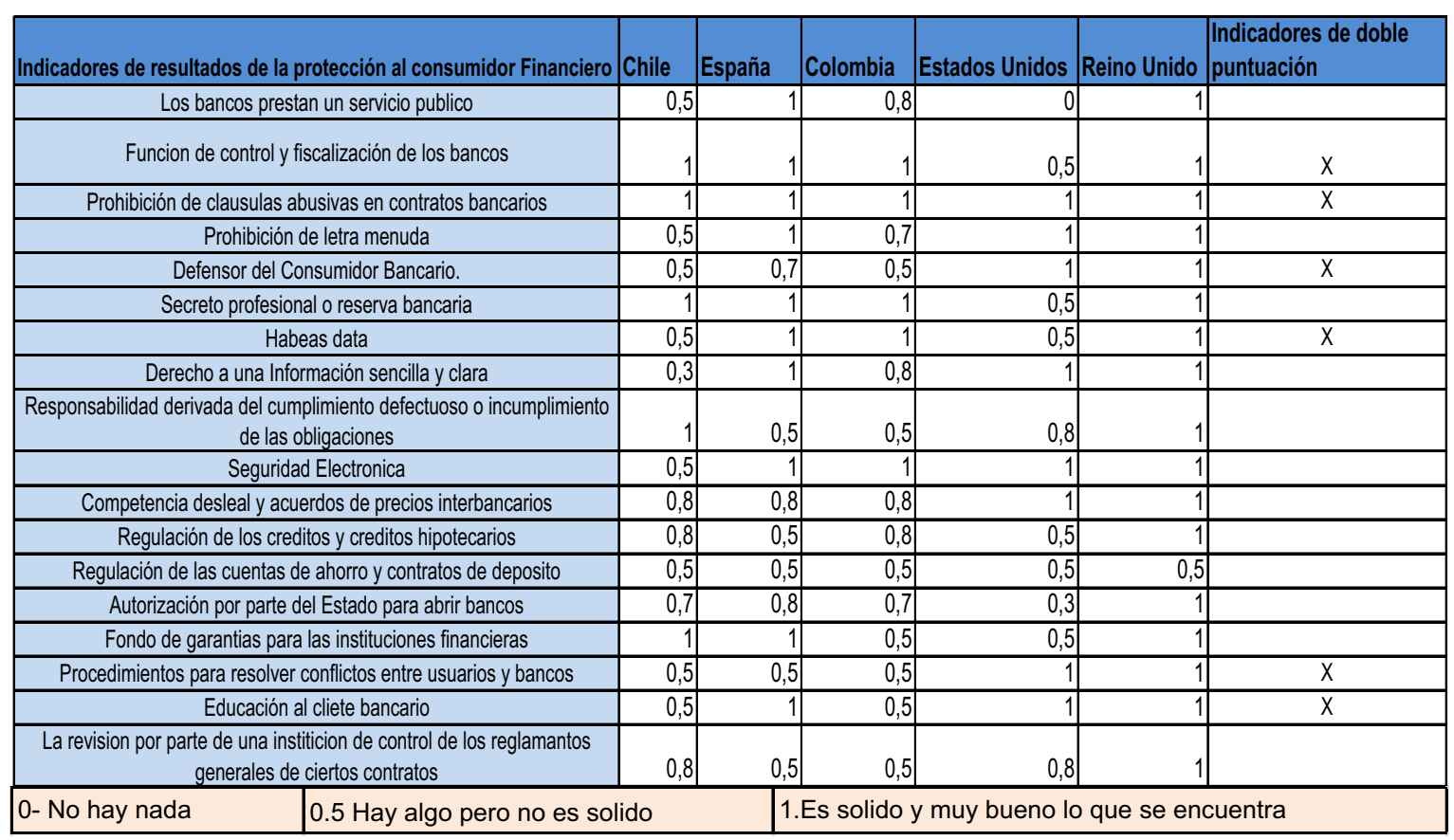

Propuesta de hipótesis causales sobre la protección del consumidor financiero.

Al realizar el análisis comparativo de los indicadores y teniendo en cuanta las diferencias entre los diferentes países, dicha situación, lleva a preguntarse por las posibles causas que lleva a los ordenamientos a ser más o menos protectores, esto hizo que se plantearan las siguientes hipótesis que se esperan que sirvan para un posterior desarrollo de la sociología del derecho.

Hipótesis 1: El interés del Estado por evitar una crisis financiera genera legislaciones más beneficiosas para los consumidores.

Cuando los Estados enfrentan crisis financieras algunos se ven abocados a proteger a los inversionistas, accionistas y usuarios para evitar un colapso en el sistema. Las crisis financieras no son algo nuevo, pero sí han demostrado que la excesiva liberalización del mercado ha provocado que los estados intervengan para generar unos determinados beneficios a aquéllos que de una u otra manera se han visto afectados, esto con el fin de recuperar la confianza del público en el sistema financiero. Dichas crisis se han intentado explicar por muchos autores con la tesis de que la respuesta a la crisis siempre ha sido cambiar las regulaciones o introducir unas nuevas, pero éstas no han sido lo suficientemente acertadas para mejorar totalmente el funcionamiento del sector (Restrepo y Núñez, 2009; Pérez, 2009, 58) dentro de estas podemos encontrar como ejemplos la crisis financiera colombiana en los años ochenta ${ }^{15}$ (Semana, 2008) y noventa ${ }^{16}$ (Fogafin, 2009; Arango, 2006). Por tanto, esperamos que los países que hayan sufrido grandes crisis financieras tengan un nivel alto de protección del consumidor financiero ${ }^{17}$. 
Hipótesis 2: El sistema financiero basado en mercado de capitales favorece o genera una legislación que protege más a los consumidores.

El sistema financiero - conjunto de instituciones, mercados e intermediarios tomando decisiones entre empresas, particulares y gobierno, facilitando el flujo entre el ahorro, crédito y financiación - se ha clasificado por la literatura en dos tipos: mercado bancario y mercado de valores. En el primero se encuentran las relaciones entre ahorradores y prestamistas intermediados por las entidades bancarias. Mientras el segundo se refiere a la posibilidad de transar o invertir por medio de agentes, una serie de títulos valores que representan bien sea acciones o inversiones a futuro. (Pérez, 2009: 50) (Dueñas, 2008) (Formación y Control, S.A. 2003) (Fradique-Méndez (2007).

Existen países en los que se desarrolla un sistema financiero basado en los bancos, al igual que, en algunos países dicho sistema está fundamentado en los mercados de valores; el sistema financiero basado en mercado de valores ha sido de raigambre antigua en países como Estados Unidos y el Reino Unido, ambos son los fundadores de las bolsas en el mundo, y han creado una serie de normas de comportamiento y asociatividad propias del mercado de valores; dicha tradición ha tenido un mayor conocimiento de las subidas y bajadas del mercado, lo que les ha permitido adaptarse a los cambios que se producen en el mercado o soportar las consecuencias propias de la forma de transacción comercial que finalmente impacta en la legislación de los estados.

Se puede mencionar la First Rule Book que fue considerado como el libro de comportamiento de la bolsa de Londres que años más tarde será reconocido por el parlamento ingles como legislación, a lo que se suma el Acuerdo de Buttonwood firmado por 24 corredores de Wall Street en Nueva York en 1817, la cual se dio su Constitución y cambió su nombre por el "New York Stock \& Exchange Board", el que sirvió como guía a los usuarios de la época y fue considerada como norma vigente en el estado de New York (Christiansen y Koldertsova, 2008).

Los constantes cambios y generación de innovaciones en el sistema de creación de inversiones a futuro presentan una serie de nuevas formas de enfrentarse a los mercados de capitales, estas innovaciones traen resultados inesperados en muchos de los casos, ponen de manifiesto el desequilibrio entre las partes o atentan directamente contra los consumidores desprevenidos o menos avezados en estas nuevas herramientas, lo que redunda en posibles crisis financieras o en pérdidas focalizadas en determinados sectores productivos, es por ello que estas imprevisiones permite que los estados en los que se desarrolle un sistema financiero basado en los mercados de valores, crea una mayor cantidad de legislaciones o prevenciones en pro del consumidor financiero.

Estas particularidades, en las que el mercado de capitales lidera las economías de los países con tradición financiera, genera nuevas formas de crear capitales, como lo son los mercados a futuro, la compra de deudas, la amortización de capitales, los bonos del tesoro, las acciones privilegiadas, venta de capitales de riesgo, y la inversión de ahorro en mercado de valores y no en inversión productiva. Para que las personas inviertan en este mercado de bonos, acciones, boceas, valores, deben tener garantizados ampliamente sus inversiones, de lo contrario no invertirian y el sistema basado en los mercados de capitales peligraría. Por tanto, en los países con un sistema financiero basado en los mercados de valores habrá alta protección del consumidor financiero. 
Hipótesis 3: Cuando se aumenta desproporcionadamente el endeudamiento de las personas, los estados reaccionan controlando mejor las actividades financieras, favoreciendo legislaciones encaminadas a proteger al consumidor.

Cuando se aumenta desproporcionadamente el endeudamiento se genera una inflación desmedida que afecta a los usuarios y que solo puede ser superada a través de la intervención y el compromiso de los Estados para mejorar las condiciones de los consumidores bancarios. Un ejemplo de ello se puede observar en los aumentos del uso de tarjetas de crédito. Esto genera situaciones masivas que se tornan en asuntos de orden público, debido al incremento masivo del endeudamiento de las personas, no solo lo comprado por ellos, sino por los tipos de interés generados por dichos medios de pago, que luego impedirán el ahorro. ${ }^{18}$

Otro ejemplo que puede tomarse es el que se da en los créditos hipotecarios, en los cuales, los deudores en busca de adquirir una vivienda se ven asaltados por el abuso en los intereses que genera un anatocismo que finalmente se dispara al no existir capacidad de pago, por el aumento inesperado de las cuotas del crédito o el aumento en el tiempo a pagar o el aumento del valor de la propiedad; esto se observo en la crisis del UPAC en Colombia, y recientemente en la crisis de Fannie Mae en los Estado Unidos conocida también como las hipotecas Subprime, debido a esta crisis, los valores respaldados por las viviendas no se ajustaban con el valor que se les prestaba a los clientes, lo que obligó a la intervención de los gobiernos tanto colombiano como de los Estados Unidos en sus respectivos momentos históricos.

Hipótesis 4: Las organizaciones internacionales, en especial las conformadas por los estados generan legislaciones más beneficiosas para los consumidores financieros.

Esto se podría corroborar con el caso de la comunidad europea que con base a sus directivas generales -Directiva CE 13/93 o Directiva 2000/12/CE del Parlamento Europeo- ha exigido a los demás países a que cumplan con la misma. Esto se aprecia en lo regulado por países como España y el Reino Unido que han acomodado su legislación en pro de dichas directivas. Estas organizaciones supranacionales logran influir en las decisiones estatales gracias a la posibilidad de establecer sanciones ante la falta de cumplimiento del mismo. Sin embargo lo normal es que se dé una aceptación racional de las órdenes que se le imparten, fundadas en el conocimiento de los objetivos finales de las mismas como lo son la posibilidad de lograr ventajas comparativas en el mercado mundial.

\section{Conclusiones.}

Con fundamento en las anteriores hipótesis se puede concluir que es interesante iniciar estudios respecto al fenómeno social de los consumidores, para este caso en el sector financiero, donde el punto central sea la sociología del derecho como referente epistemológico y conceptual, ya que dicho enfoque permite no solo tener en cuenta el aspecto normativo del derecho, sino dar explicaciones sobre la existencia de ciertas normas en los ordenamientos jurídicos, sus aciertos, y su capacidad para regular aspectos de la realidad social.

La sociología puede contribuir al derecho de los consumidores financieros, tanto desde la parte metodológica por medio del uso de instrumentos, como; análisis cualitativos, cuantitativos, comparativos, el uso de la estadística, encuestas, entrevistas; así como desde los marcos teóricos propios de esta disciplina: tales como estudios sobre la cultura, 
estructurales y de sociología económica. Además, este artículo presenta una inquietud inicial para que a partir de la sociologia del derecho puedan abrirse paso a investigaciones sobre este tema que consideren asuntos como: establecer, sí las promulgaciones indiscriminadas de normas, sí protegen efectivamente al consumidor financiero, y profundizar en las causas que hacen que algunas legislaciones protejan de mejor manera a los consumidores financieros, dejando los siguientes interrogantes; ¿Son estas legislaciones aplicadas de la manera adecuada? ¿Existen dificultades entre la creación y la aplicación de estas normas? ¿Cuáles son las lógicas que se preservan en estas regulaciones? y ¿cuál es la interconexión entre el entorno social de los consumidores y las normas que los protegen? 


\section{Referencias Bibliográficas.}

Acharya, Viral V. and Richardson, Matthew. (2008). Restoring Financial Stability: How to Repair a Failed System, An Independent View from New York University Stern School of Business. New York. December 2008. En:

http://media.wiley.com/assets / 1706/87/NYU_Stern_Executive_Summaries.pdf.

AFP (2011). "Indignados" londinenses acampan en la plaza de Trafalgar, Londres, Inglaterra, Publicado el 09 Noviembre 2011 - 10:30 a.m.

http://www.eluniversal.com.co/cartagena/internacional/indignados-londinensesacampan-en-la-plaza-de-trafalgar-52438.

Arango, Miguel. (2006). Evolución y crisis del sistema financiero colombiano. Bogotá, D.C., Colombia, junio de 2006. CEPAL. SERIE Estudios y perspectivas $\mathrm{N}^{\circ} 11$.

Arias Barrera, Ligia Catherine. (2008). Derecho del consumidor y su aplicación en el sector financiero.En: REVIST@e-Mercatoria Volumen 7, Número 1 (2008) en:http:/ / www.emercatoria.edu.co/PAGINAS/VOLUMEN7 / PDF01/consumidor.pdf

Banco de España - Eurosistema (2008) Comisión Nacional del Mercado de Valores. Plan de Educación Financiera 2008-2012. En:

http://www.bde.es/webbde/es/secciones/prensa/EdU_Financiera_final.pdf.

Bartels Villanueva, Jorge y Arias Alpízar, Luz Mary. El secreto bancario Aspectos históricos y problemática actual. En: Diálogos, Revista Electrónica de Historia, ISSN: 1409-469X, Vol. $11 \mathrm{~N}^{\circ} 1$, setiembre 2010, febrero 2011. / pp. 67-88.

Baudrillard, Jean. (1979). Critica de la economía política del signo. Siglo veintiuno editores. México. 1979.

Baudrillard, Jean. (1974). La sociedad de consumo, sus mitos, sus estructuras. Plaza \& Janes. Barcelona. 1974.

Bauman, Zygmunt. (2007). Vida de Consumo. Buenos Aires. Fondo de Cultura Económica.

Benjamin, Antonio Herman. (1991). El derecho del consumidor. En: revista de los Tribunales. Agosto de 1991. Vol 670. Fase1 "civil" Brasil.

Beretta, Simona. (2009). Los modelos de regulación de los mercados financieros: el mensaje de la encíclica. En: revista Cultura económica. Año XXVII. N 75/76. Agosto diciembre de 2009. p44-76.

Buckley, Cara and Donadio Rachel. (2011). Buoyed by Wall St. Protests, Rallies Sweep the Globe New York, New York Times. October 15, 2011 en:

http: / www.nytimes.com/2011/10/16/world/occupy-wall-street-protestsworldwide.html?_r=1\&scp=8\&sq=times\%20square\&st=cse. 
Bustelo, Pablo. (2001). Los orígenes de la crisis financiera de Argentina: una comparación con las crisis asiáticas. En; Boletín Económico de Información Comercial Española $\mathrm{n}^{\circ}$ 2715, 7-13 de enero de 2002, pp. 9-14

En:http://www.ucm.es/info/eid/pb/BusteloArg02.pdf.

Christiansen, Hans \& Koldertsova, Alissa (2008). The role of stock exchanges in corporate Governance. En: financial market trends. OECD. Vol. 2009/1 En:

http://www.oecd.org/dataoecd/3/36/43169104.pdf.

Cortina, Adela. (2002). Por una ética del consumo. Taurus. Madrid. 2002.

Cueto, Juan. (1985). La sociedad de consumo de masas. Salvat editores s.a. Madrid. 1985.

Demirguc-Kunt, Asli and Levine, Ross, (1999). Ross Bank-based and market-based financial systems: cross-country comparisons. The World Bank, and Finance Department, University of Minnesota. Minnesota. En:

http://siteresources.worldbank.org/INTFR/Resources/475459-1 08132178926/Kunt_Levine.pdf.

DiMartino, Danielle \& Duca, John V. (2007) The Rise and Fall of Subprime Mortgages.EconomicLetter. Federal Reserve Bank of Dallas. Vol. 2, No. 11 November 2007. En: http://dallasfed.org/research/eclett/2007/el0711.pdf.

Dueñas Prieto, Ricardo (2008). Introducción al sistema financiero y bancario. Bogotá. Politécnico Grancolombiano En: http://crear.poligran.edu.co/publ/00008/SFB.pdf.

El Mundo.es, (2011). Renace el espíritu del 15-M con una respuesta masiva en las calles de España en:

http://www.elmundo.es/elmundo/2011/10/15/espana/1318669970.html.

El FIDA y el Fondo OPEP (2006) Una alianza para erradicar la pobreza rural. En: http://www.ifad.org/pub/opec/ifad_opec_s.pdf.

Engel, Eduardo. (1998). Protección de los consumidores en chile: ¿por qué tan poco y tan tarde?. SERIE ECONOMIA No 35. Julio, 1998. Centro de Economía Aplicada. Departamento de Ingeniería Industrial. Facultad de Ciencias Físicas y Matemáticas. Universidad de Chile En:

http://www.webmanager.cl/prontus_cea/cea_1998/site/asocfile/ASOCFILE1200 30403114939.pdf.

Federación Latinoamericana De Bancos -FELABAN- (2007). Prácticas de Buen Gobierno Corporativo en el Sector Financiero Latinoamericano.

Ferrer, Aldo. (1999). La Globalización, la crisis financiera y América Latina. En: Tiempos violentos; Neoliberalismo, globalización y desigualdad en América Latina. Comp. Boron, Atilio A.; Gambina, Julio; Minsburg, Naum. Coleccion CLACSO - EUDEBA, CLACSO, Consejo Latinoamericano de Ciencias Sociales, Ciudad de Buenos Aires, Argentina. Abril 1999. 87-107. En:

http://168.96.200.17/ar/libros/tiempos/ferrer.rtfE-mail: . 
Fradique-Méndez, Carlos. (2008). Guía del mercado de valores. Bogotá. Bolsa de Valores de Colombia y Banco Interamericano de Desarrollo. p. 250 En:

http://www.valoresbancolombia.com/cs/Satellite?blobcol=urldata\&blobheaderna me1=content-type\&blobheadername2=Content-

Disposition\&blobheadername3=MDT-

Type\&blobheadervalue $1=$ application $\% 2$ Fpdf\&blobheadervalue $2=$ inline $\% 3 \mathrm{~B}+$ filena me\%3Dmyfile\&blobheadervalue 3=abinary\%253B\%2Bcharset\%253DUTF-

8\&blobkey $=$ id\&blobtable $=$ MungoBlobs\&blobwhere $=1266523124195 \&$ ssbinary $=$ true

Fogafin. (2009). Crisis financiera colombiana en los años noventa. Origen, resolución y lecciones institucionales. Bogotá. Universidad Externado de Colombia. p. 322 .

Fondo Monetario Internacional. (1999). Código de buenas prácticas de transparencia en las políticas monetarias y financieras: declaración de principios. En:

http://www.imf.org/external/np/mae/mft/code/spa/code2s.pdf.

Fondo Monetario Internacional. (2000). Documento complementario del Código de buenas prácticas de transparencia en las politicas monetarias y financieras. En: http://www.imf.org/external/np/mae/mft/sup/esl/part1s.pdf.

Formación y Control, S.A. (2003). Sistema Financiero Español en:

http:/ /www.ugtcajasol.es/CD\%200posiciones/Auxiliares\%20Monte/Sistema\%20F inanciero\%20Monte.pdf.

García C, Nestor. (1995). Consumidores y ciudadanos. Grijalbo. México. 1995.

García Neumann, Jaime. (2010). La especulación financiera como delito contra la humanidad. Fundamentos en la historia de la economía. En: Via Inveniendi Et Iudicandi. Edición No. 12 Vol. 6 No. 2. Julio - Diciembre de 2011.

García Neumann, Jaime. (2009a). "Crisis global y cambios de paradigma. El papel de la filosofia ante la crisis mundial”. VII Jornadas de Diálogo Filosófico, U. de Salamanca.

Gonçalves, Leonardo \& Sawaya, Alexandre. (2011). Creating value through credit card partnerships in Latin America. McKinsey on Payments.

González Barrera, Pedro Pablo \& Patrón Galvis, José Carlos. (2007). Centros Financieros Offshore. (Monografia) Universidad Colegio Mayor de Nuestra Señora del Rosario. Facultad de Jurísprudencia. Bogotá D.C.

La Porta, Rafael., Lopez-de-Silanes, Florencio., Shleifer, Andrei \& W. Vishny Robert. (1996). Law and finance. NBER working paper series 5661. National Bureau of Economic Research. Massachusetts July 1996 en: http:/ /www.nber.org/ papers/w5661.pdf.

Livacic, Ernesto., Sáez, Sebastián. (2001). La agenda de la supervisión bancaria en América Latina. En: Revista CEPAL No 74. p. 125-138. En:

http://www.eclac.org/publicaciones/xml/7/5167/lc11434e.pdf. 
Mackay, Charles (1848). Memoirs of Extraordinary Popular Delusions and the Madness of Crowds. London: Office of the National Illustrated Library 1999 edition electronic Chapter 3. The Tulipomania .

Mendoza, Carlos A. (2010). Estudio sobre Protección para los Usuarios del Sistema Financiero. Central American Business Intelligence, CABI. En: http://cabi.com/blackbox/wp-content/uploads/downloads / 2010/07 / DocumentoPrincipal.pdf.

Nanto, Dick K. Coordinator (2009). The Global Financial Crisis: Analysis and Policy Implications. Congressional Research Service 7-5700 RL34742 Prepared for Members and Committees of Congress. En:

http://www.fas.org/sgp/crs/misc/RL34742.pdf.

OECD, Organization for Economic Co-operation and Development. (2011). G20 High-Level Principles On Financial Consumer Protection. October 2011 http://www.oecd.org/dataoecd/58/26/48892010.pdf .

Pardos Vicente. (1998). Los servicios financieros en la U.E. En: revista valenciana d'etudis autonònics. Numero 23 - segundo trimestre 1998. p. 203-228.

Paul, Helen. (2004). The South Sea Company's slaving activities. Inglaterra University of St. Andrews En: http://www.ehs.org.uk/ehs/conference2004/assets/paul.doc.

Pérez Ramírez, Jorge. (2009). Banca y contabilidad historia, instituciones, riesgos y normas internacionales IFRS. España. Marcial Pons. p. 511.

Pecora Investigation Hearings- Also known as Stock Exchange Practices.(SD) Hearings before the Committee on Banking and Currency Pursuant to S.Res. 84 and S.Res. 56 and S.Res. 97. The full-text of these hearings are posted on the FRASER website of the Federal Reserve Bank of St. Louis in searchable pdf format. En: http://fraser.stlouisfed.org/docs/publications/sensep/19340606_sensep_rpt.pdf.

Pinar Ardic, Oya., Ibrahim, Joyce A. \& Mylenko, Nataliya (2011) Consumer Protection Laws and Regulations in Deposit and Loan Services A Cross-Country Analysis with a New Data Set. En: Policy Research Working Paper WPS5536. The World Bank Financial and Private Sector Development Consultative Group to Assist the Poor January 2011W. En:

http:/ /www.cgap.org/gm/document-

1.9.49436/Consumer_Protection_Laws_and_Regulations_In_Deposit_and_Loan_Se rvices.pdf.

Restrepo, Juan Camilo, y Núñez, Antonio José (2009). Diálogos sobre las crisis financieras. Medellin. Dike. p. 313.

Ritzer, George. (2000). El encanto de un mundo desencantado: revolución en los medios de consumo. Ariel Sociedad Económica. Barcelona. 
Rojas Aravena,Francisco. (2009). Crisis financiera construyendo una respuesta política latinoamericana. V Informe del Secretario General de FLACSO. San José, Costa Rica FLACSO, 2009. 92 p. En: http://www.flacso.org/fileadmin/usuarios/documentos/FIN_DE_ANO/V\%20Infor me.pdf.

Semana.com. (2008). Punto Final. Bogotá. Semana, en: http:/ /www.semana.com/wf_ImprimirArticulo.aspx?IdArt=88643.

Semana.com. (1983). Crisis financiera. Bogotá. Semana,Lunes 31 Enero 1983 en: http://www.semana.com/nacion/crisis-financiera/61309-3.aspx.

Sentencia tribunal supremo de justicia, (2004) republica bolivariana de Venezuela, magistrado ponente Jesús Eduardo Cabrera Romero. EXP. Nº 04 -0204.

Serna Gómez, Humberto., Suárez Ortiz, Edgar. \& Restrepo Campiño, Mónica María. (2007). Prácticas de Buen Gobierno Corporativo en el Sector Financiero Latinoamericano. Bogotá.Federación Latinoamericana De Bancos FELABAN. En: http://www.felaban.com/archivos_publicaciones/buen_gobierno.pdf

Serrano Leal, Cristina, Montoro Zulueta, Begoña \& Mulas Alcántara, Marta. (2010). La respuesta de la Unión Europea ante la crisis económica. El Plan Europeo de Recuperación Económica. en: Boletín económico de ICE Nº 2988 del 1 al 15 de mayo de 2010, p.15-32.

Superintendencia Bancaria de Colombia. (2011). Información Estadística - Mensual http://www.superfinanciera.gov.co/.

The financial crisis inquiry commission. (2011). Final Report of the National Commission on the Causes of the Financial and Economic Crisis in the United States. Washington. January 2011 en: http:/ / www.gpo.gov/fdsys / pkg/GPO-FCIC/pdf/GPO-FCIC.pdf.

UNCTAD. (2009). The Global Economic Crisis: Systemic Failures and Multilateral Remedies. UNCTAD/GDS/2009/1. United Nations conference on trade and development. p.80 En: http://www.unctad.org/en/docs/gds20091_en.pdf.

World Bank. (2008). Good Practices for Consumer Protection and Financial Literacy in Europe and Central Asia: A Diagnostic Tool October 2008. THE WORLD BANK. Private and Financial Sector Development Department Europe and Central Asia Region. Washington, DC. En: http://www.ecri.be/new/system/files/World_BankGood_practices_for_consumer_protection_Consultative_draft-8Oct08.pdf.

Venegas Calle, Stella Del Pilar (2010). La crisis económica de 2008 algunas reflexiones teóricas a partir de J.M. keynes y H. P. Minsky. En Revista Criterio Libre Vol. 8 No. 12 Bogotá (Colombia) Enero - Junio 2010 Pp. 93-114.

Yunus, Muhammad. (2005). El banquero de los pobres: los microcréditos y la batalla contra la pobreza en el mundo. España. paidos iberica, p.384.

Zajac, (2011). SP. En: Revista Forbes. htpp: www.revistaforbes.com. 
2"A la luz de estas cuestiones, la protección del consumidor financiero debe reforzarse e integrarse con la inclusión de otras instituciones financieras y políticas de educación financiera. Esto contribuye a reforzar la estabilidad financiera "Para profundizar este tópico ver: en: G20 High-Level Principles On Financial Consumer Protection. October 2011. http://www.oecd.org/dataoecd/58/26/48892010.

${ }^{3}$ Dentro de ellas se encuentra a los autores Ernesto Livacic y Sebastián Sáez, consultores del proyecto "Mejoramiento de la capacidad en materia de políticas de desarrollo económico y social en los países de América Latina y el Caribe", CEPAL"

${ }^{4}$ Dentro de estos estudios se puede encontrar el de la FLACSO que en cabeza de su secretario general Rojas Aravena, Francisco. (2009) realiza un informe técnico donde se estudian las variables económicas del desarrollo, las oportunidades, el desempleo y el acceso al crédito entre otras.

${ }^{5}$ Los distritos están conformados por los bancos de Boston; New York; Philadelphia; Cleveland; Richmond; Atlanta; Chicago; St. Louis; Minneapolis; Kansas City; Dallas; San Francisco y el Seattle Branch sirve a Alaska, y el San Francisco Bank sirve a Hawaii. E1 sistema sirve a mancomunidades y territorios de la siguiente manera: el banco de Nueva York sirve a la Comunidad de Puerto Rico y las Islas Vírgenes de los EE.UU., el Banco de San Francisco sirve a la Samoa Americana, Guam, y la Comunidad de las Islas Marianas del Norte. La Junta de Gobierno revisó los límites rama del sistema en febrero 1996.

${ }^{6}$ Actualmente los miembros de la mesa de gobernadores son; Ben S. Bernanke, Chairman; Janet L. Yellen, Vice Chair; Elizabeth A. Duke; Daniel K. Tarullo; Sarah Bloom Raskin. The seven members of the Board of Governors of the Federal Reserve System are nominated by the President and confirmed by the Senate. A full term is fourteen years. One term begins every two years, on February 1 of even-numbered years. A member who serves a full term may not be reappointed. A member who completes an unexpired portion of a term may be reappointed. All terms end on their statutory date regardless of the date on which the member is sworn into office.

${ }^{7}$ Specific conditions: private sector purchaser and bridge bank (1) The Bank of England may exercise a stabilisation power in respect of a bank in accordance with section 11(2) or 12(2) only if satisfied that Condition A is met. (2) Condition A is that the exercise of the power is necessary, having regard to the public interest in - (a) the stability of the financial systems of the United Kingdom, (b) the maintenance of public confidence in the stability of the banking systems of the United Kingdom, or (c) the protection of depositors.

${ }^{8}$ Exercise of powers: general 7 General conditions (1) A stabilisation power may be exercised in respect of a bank only if the FSA is satisfied that the following conditions are met. (2) Condition 1 is that the bank is failing, or is likely to fail, to satisfy the threshold conditions (within the meaning of section 41(1) of the Financial Services and Markets Act 2000 (permission to carry on regulated activities). 
${ }^{9} \mathrm{E} 1$ Artículo17 se va referir a este asunto de la siguiente manera "Los contratos de adhesión relativos a las actividades regidas por la presente ley deberán estar escritos de modo legible y en idioma castellano, No obstante lo previsto en el inciso primero, tendrán validez los contratos redactados en idioma distinto del castellano cuando el consumidor lo acepte expresamente, mediante su firma en un documento escrito en idioma castellano anexo al contrato, y quede en su poder un ejemplar del contrato en castellano, al que se estará, en caso de dudas, para todos los efectos legales"

${ }^{10}$ En el artículo 80 se menciona que debe existir "Concreción, claridad y sencillez en la redacción, con posibilidad de comprensión directa, sin reenvios a textos o documentos que no se faciliten o simultáneamentea la conclusión del contrato, y a los que, en todo caso, deberá hacerse referencia expresa en el documento contractual". Además de garantizarse la "Accesibilidad y legibilidad, de forma que permita al consumidor y usuario el conocimiento previo a la celebración del contrato sobre su existencia y contenido"

${ }^{11} \mathrm{La}$ autoridad del Gobierno pueden tener acceso u obtener copias de la información contenida en los registros financieros de cualquier cliente de una entidad financiera a menos que los registros financieros no sea razonablemente descrita

${ }^{12}$ Los resultados y el propósito, b) El propósito de este título es ofrecer un marco básico que estableca los derechos, obligaciones y responsabilidades de los participantes en los sistemas electrónicos de transferencia de fondos. El objetivo principal de este título, sin embargo, es la provisión de los derechos individuales de los consumidores"

${ }^{13}$ Esto se puede encontrar en la siguiente dirección electrónica http://www.boe.es/boe/dias/2012/07/06/pdfs/BOE-A-2012-9058.pdf

${ }^{14}$ "Memorandum of Understanding between HM Treasury, the Bank of England and the Financial Services Authority", available from http://www.bankofengland.co.uk/financialstability/mou.pdf y en http://www.publications.parliament.uk/pa/ld200809/ldselect/ldeconaf/101/10108.htm

${ }^{15}$ La revista Semana realiza un reportaje sobre el mismo y en él se cuenta que "Correa Maya, uno de los más brillantes hombres de negocios en la historia del país, fue la cabeza del Grupo Colombia, conformado por 60 empresas financieras e industriales. Todas gravitaban en torno al Banco Nacional, la sociedad Correa Acevedo y la Financiera Furatena, entidades que en junio de 1982 fueron intervenidas por la Superintendencia Bancaria, hecho que desencadenó en la llamada 'crisis financiera' de los años 80. Posteriormente, y en condiciones más o menos similares, otros importantes financistas también se derrumbaron en medio de los escándalos y terminaron en la cárcel mientras sus empresas se iban a pique. Entre ellos figuran Jaime Mosquera, del Grupo del Banco del Estado; Eduardo Uribe de Narváez, del Grupo Central, y hasta una persona de la talla de Jaime Michelsen Uribe, del Grupo Grancolombiano."

${ }^{16}$ Para Miguel Arango, dicha crisis se originó debido a "la liberalización financiera, él boom crediticio, él deterioro de los términos de intercambio, la revaluación constante durante la década, la reducción de los precios de los activos, él incremento de la tasas de interés al final de la década, la deficiente regulación del sector hipotecario y cooperativo y, principalmente y en forma fundamental, la repentina y abrupta suspensión de los flujos de capital externos" 
${ }^{17}$ Banks lack the equity capital needed to hold large volumes of these risky loans in their portfolios. And lenders of all types couldn't originate and then sell these loans to investors in the form of residential mortgage-backed securities, or RMBS-at least not without added protection against defaults. The spread of new products offering default protection was the second crucial development that fostered subprime lending growth. Traditionally, banks made prime mortgages funded with deposits from savers. By the 1980s and 1990s, the need for deposits had eased as mortgage lenders created a new way for funds to flow from savers and investors to prime borrowers through government-sponsored enterprises (GSEs) (Chart 2 , upper panel). This is where financial innovations came into play. Some-like collateralized debt obligations (CDOs), a common RMBS derivative-were designed to protect investors in nonagency securities against default losses. Such CDOs divide the streams of income that flow from the underlying mortgages into tranches that absorb default losses according to a preset priority.

${ }^{18}$ Esta utilización masiva de las tarjetas, promocionadas publicitariamente, y coercitivamente impulsada en algunos casos, hacen que la tomen mayoritariamente los miembros de las clases sociales media y alta, quienes no sólo se ven compelidos al consumo, sino que pueden hacer nula o disminuir su capacidad de ahorro. Esta situación -a juicio de la Sala- da al uso de las tarjetas un contenido social, que merece la atención del Estado, máxime cuando el Estado es social de derecho y de justicia (artículo 2 constitucional), y los consumidores de las tarjetas pertenecen a clases sociales, cuyos miembros, al pertenecer a esos sectores sociales, también requieren protección en su calidad de vida. Sentencia tribunal supremo de justicia, república bolivariana de Venezuela, magistrado ponente Jesús Eduardo Cabrera Romero. EXP. $\mathrm{N}^{\circ}$ : $04-0204$ 